\title{
Overexpressed PLAGL2 transcriptionally activates Wnt6 and promotes cancer development in colorectal cancer
}

\author{
NANPENG LI*, DAOJIANG LI*, YUHENG DU, CHEN SU, CHUNXING YANG, \\ CHANGWEI LIN, XIAORONG LI and GUI HU \\ Department of Gastrointestinal Surgery, The Third Xiangya Hospital of Central South University, \\ Changsha, Hunan 410013, P.R. China
}

Received May 12, 2018; Accepted November 28, 2018

DOI: 10.3892/or.2018.6914

\begin{abstract}
Researchers hold the view that PLAGL2 is overexpressed in many malignancies and that it can promote tumor proliferation, migration, invasion and self-renewal; however, there is no evidence revealing a relationship between PLAGL2 and colorectal cancer $(\mathrm{CRC})$. In the present study, genes that are overexpressed in CRC were screened using the COSMIC database and GEPIA database and the expression of PLAGL2 in carcinoma tissues and pericarcinomatous tissues was detected by RT-qPCR and western blot assays. A Cell Counting Kit- 8 assay, a cell cycle analysis experiment and a xenograft model were used to explore the influence of PLAGL2 on CRC after knocking down PLAGL2 expression in HCT116 and SW480 cells. Using ChIP assays and Dual-Luciferase Reporter assays, the promoter regions to which PLAGL2 binds were discovered. It was observed that PLAGL2 was overexpressed in colorectal cancer and that it influenced the colorectal cancer cell cycle and promoted colorectal cancer proliferation in vivo and in vitro. The expression of some genes in the Wnt/ $\beta$-catenin pathway, were downregulated after knocking down the expression of PLAGL2; Wnt6 was altered the most. PLAGL2 could bind to the promoter region of Wnt6 and promote its expression. These results indicated that PLAGL2 was overexpressed in CRC as a proto-oncogene and that it could active the Wnt/ $\beta$-catenin pathway as a transcription factor by binding with the promoter region of Wnt6. PALGL2 was revealed to play an important role in colorectal cancer and may be a new therapeutic target for targeted medicine.
\end{abstract}

\section{Introduction}

According to the survey results published by the American Cancer Society (ACS), colorectal cancer (CRC) is one of the

Correspondence to: Dr Gui Hu, Department of Gastrointestinal Surgery, The Third Xiangya Hospital of Central South University, 172 Tongzi Po Road, Changsha, Hunan 410013, P.R. China

E-mail: hugui0202@qq.com

${ }^{*}$ Contributed equally

Key words: PLAGL2, colorectal cancer, Wnt//-catenin pathway, Wnt6 most common tumors worldwide. The incidence rate is ranked third among cancers (1). The number of deaths attributed to colorectal cancer each year still reaches 610,000 (2), ranking it second in malignant tumors (1).

Polymorphic adenoma-like protein 2(PLAGL2) is a zinc finger protein of the PLAG gene family with $7 \mathrm{C} 2 \mathrm{H} 2$ zinc finger domains on the N-terminus (3-5). This structure is highly conserved, can bind DNA and enables the transcription factor PLAGL2 to activate the transcription of specific genes (6). PLAGL2 is closely related to the development of malignant tumors. PLAGL2 is important in the development of acute myeloid leukemia (7), lung cancer (8), glioma (9), prostate cancer (10) and other tumors. In colorectal cancer, Liu et al (11) selected 225 pairs of colon cancer tissues and 66 normal tissues for immunohistochemical studies and found that PLAGL2 expression was significantly increased in colorectal cancer. The mechanism of how PLAGL2 regulates the development of colon cancer has not been clearly elucidated.

In our previous study, causes of high PLAGL2 expression in colorectal cancer were initially addressed (12). The aim of the present study was to investigate the mechanism by which PLAGL2 affects the development of colorectal cancer.

\section{Materials and methods}

Tissue specimens. All 31 CRC tissue specimens and pericarcinomatous tissues were collected from the Third Affiliated Hospital of Central South University between January 2017 and May 2017 (Changsha, China). There are 15 female and 16 male patients and their age ranged from 35 to 70 years. All tissues were immediately flash-frozen in liquid nitrogen after resection and were then stored in liquid nitrogen. All cases were diagnosed as colorectal cancer (CRC) by pathological sections, and the patients received no chemo-, radio- or hormone therapy. All the patients signed consent forms. The present study was approved by the Institute Research Medical Ethics Committee of Central South University (Changsha, China).

Animals. BALB/C nude mice ( $\mathrm{n}=24$, female, 5-weeks-old and 16-20 g) were purchased from the SJA Laboratory Animal Company (Changsha, China) and housed under specific pathogen-free conditions with a 12-h light/dark cycle and autoclaved food/water were provided freely. The LV-PLAGL2-Homo-808 or LV-Vector (Shanghai GenePharma 
Co., Ltd., Shanghai, China) was stably transfected in SW480 and HCT116 cells following the manufacturer's instructions, and a suspension of transfected-cells [5x10 in $100 \mu$ l phosphate-buffered saline (PBS)] was injected into nude mice $(n=6$ for each group). Three groups were injected with HCT116 cells (mock, LV-Vector and LV-PLAGL2-Homo-808). The tumor volume was assessed every three days beginning 10 days after the injection and was calculated with the following formula: Tumor volume $\left(\mathrm{mm}^{3}\right)=\left(\right.$ length $\mathrm{x}$ width $\left.{ }^{2}\right) / 2$. All mice were sacrificed 30 days later by cervical dislocation after the mice were anaesthetized, and all animal protocols in this study were approved by the Animal Ethics Committee of Central South University (Changsha, China).

Cell culture. The human CRC cell lines SW480 and HCT116 were purchased from Wuhan Boster Biological Technology Ltd. (Wuhan, China). SW480 cells were cultured in L15 medium (Nanjing KeyGen Biotech Co., Ltd., Nanjing, China) containing 10\% fetal bovine serum (FBS) (Biological Industries, Kibbutz Beit-Haemek, Israel). HCT116 cells were cultured in McCoy's 5A medium (Nanjing KeyGen Biotech Co., Ltd.) containing $10 \%$ FBS. All cells were cultured in a humidified incubator at $37^{\circ} \mathrm{C}$ and $5 \% \mathrm{CO}_{2}$.

Plasmid and lentivirus constructs. The human CRC cell lines SW480 and HCT116 were transfected with three different vectors, which were transferred by lentivirus, targeting PLAGL2 to knock down PLAGL2 protein expression. Three short hairpin RNAs targeting human PLAGL2 and a non-targeting RNA sequence serving as a negative control were cloned into the pGPU6 vector (Shanghai GenePharma Co., Ltd., Shanghai, China). The details of the RNA sequences are presented in Table I. Virus packaging was performed in 293T cells. SW480 and HCT116 cells were cultured in 6-well plates with normal medium containing $10 \%$ FBS the day before transfection $\left(5 \times 10^{5}\right.$ cells/plate). After $24 \mathrm{~h}$, the cells were transfected with $50 \mu \mathrm{l}$ lentivirus with $5 \mu \mathrm{l}$ Polybrene $(5 \mu \mathrm{g} / \mathrm{ml})$ and $1.5 \mathrm{ml}$ medium. The cells were selected for 5 days and then used for various assays. The lentivirus and vectors were purchased from Nanjing KeyGen Biotech Co., Ltd.

Full-length human WNT6 cDNA (NM_006522.3) was cloned into the pCMV vector (Shanghai GenePharma Co., Ltd.). Virus packaging and transduction were performed as aforementioned. WNT6 was ovexpressed in HCT116 cells as PLAGL2 was knocked down. In addition, WNT6-overexpressed-cells were cultured in McCoy's 5A medium (Nanjing KeyGen Biotech Co., Ltd.) without FBS.

Western blotting (WB). Total protein was extracted by lysis in RIPA buffer (Nanjing KeyGen Biotech Co., Ltd.) containing protease inhibitor cocktail (Nanjing KeyGen Biotech Co., Ltd.) for $15 \mathrm{~min}$ at $4^{\circ} \mathrm{C}$ and centrifuged at $16,666 \mathrm{x}$ g for $15 \mathrm{~min}$ at $4^{\circ} \mathrm{C}$. The proteins were measured by BCA assay. Proteins $(40 \mu \mathrm{g})$ were separated by $10 \%$ SDS-PAGE and transferred to polyvinylidene difluoride (PVDF) membranes.

The membranes were blocked with $5 \%$ non-fat milk in PBS for $2 \mathrm{~h}$ at room temperature and were then incubated with primary antibodies at $4^{\circ} \mathrm{C}$ overnight. Subsequently, the membranes were incubated with IRDye $800 \mathrm{CW}$ conjugated goat (polyclonal) anti-rabbit $\mathrm{IgG}(\mathrm{H}+\mathrm{L})$ (dilution 1:15,000; cat. no. 926-32211; LI-COR Biosciences, Lincoln, NE, USA) for $2 \mathrm{~h}$ at room temperature. The protein bands were visualized by Infrared fluorescence with Odyssey CLx (LI-COR Biosciences) and the excitation wavelength was $778 \mathrm{~nm}$. The primary antibodies used were as follows: Anti-PLAGL2 (cat. no. ab139509) and anti-Wnt6 (cat. no. EPR9244) (both from Abcam, Cambridge, UK), anti- $\beta$-catenin (cat. no. 8480) (Cell Signaling Technology, Danvers, MA, USA) at a 1:1,000 dilution; anti-GAPDH (cat. no. ab181602; Abcam) at a 1:3,000 dilution at a 1:3,000 dilution.

Quantitative real-time PCR (RT-qPCR). Total RNA was extracted by TRIzol reagent (Invitrogen; Thermo Fisher, Scientific, Inc., Waltham, MA, USA). Real-Time Quantitative PCR (RT-qPCR) was performed with the Toyobo RT kit and KOD SYBR ${ }^{\circledR}$ qPCR kit (Toyobo Life Science, Osaka, Japan) according to the manufacturer's protocol. The primers for mRNA were produced by Sangon Biotech Co., Ltd. (Sangon Biotech, China) and the primer sequences are listed in Table II. The thermocycling conditions are listed in Table III. All mRNA expressions were standardized to GAPDH, and the mRNA levels were determined by the $2^{-\Delta \Delta \mathrm{Cq}}$ method. The method of quantification employed by Livak and Schmittgen (13).

Cell Counting Kit-8 assay. Cell proliferation was assessed by a Cell Counting Kit-8 assay (CCK-8 Kit; Dojindo Laboratories, Kumamoto, Japan). After cells were stably transfected with lentivirus, which included the vectors to knock down the expression of PLAGL2, the cells $\left(4 \times 10^{3}\right.$ cells/well) were incubated in normal medium without serum at $37^{\circ} \mathrm{C}$ overnight the day before and incubated in 96-well plates with $100 \mu \mathrm{l}$ normal culture medium at $37^{\circ} \mathrm{C}$. At the indicated time-points $(12$, 24, 48, 72 and $96 \mathrm{~h}$ ), $10 \mu \mathrm{l}$ of CCK-8 solution was added into each well and then cultured for $3 \mathrm{~h}$ at $37^{\circ} \mathrm{C}$. The absorbance of each well at $450 \mathrm{~nm}$ (A450) was detected with an EnVision microplate reader (PerkinElmer, Inc., Waltham, MA, USA). All experiments were performed in triplicate.

Cell cycle analysis experiment. Cells were plated into a 6-well plate at a density of $3 \times 10^{5}$ cells/well for $24 \mathrm{~h}$ and fixed with $2 \mathrm{ml} 1 \%$ paraformaldehyde and stored in $70 \%$ ethanol at $-20^{\circ} \mathrm{C}$. The cells were stained with $0.5 \mathrm{ml} \mathrm{PI} / \mathrm{RNase}$ (BD Biosciences, Fraklin Lakes, NJ, USA) staining buffer for $15 \mathrm{~min}$ at room temperature and analyzed by flow cytometry.

Immunofluorescence. A total of $3 \times 10^{5}$ cells were plated into the 24-well plates for $24 \mathrm{~h}$ at $-20^{\circ} \mathrm{C}$ and each well was covered by a glass coverslip. Cells were fixed in $4 \%$ paraformaldehyde for $24 \mathrm{~h}$ at room temperature and blocked in 10\% BSA for $2 \mathrm{~h}$ at room temperature. Cells were labeled with anti-PLAGL2 antibodies (dilution 1:100; cat. no. 139509; Abcam) at $4^{\circ} \mathrm{C}$ for $12 \mathrm{~h}$. The following day, the cells were stained for $1 \mathrm{~h}$ with cy3-labeled goat anti-rabbit IgG (dilution 1:100; cat. no. KGIF010; Nanjing KeyGen Biotech Co., Ltd.) at $37^{\circ} \mathrm{C}$ and slides were washed three times for 5 min with PBS. Nuclei were stained with DAPI (Nanjing KeyGen Biotech Co., Ltd.) for $5 \mathrm{~min}$ at $37^{\circ} \mathrm{C}$. PLAGL2 immunofluorescence was imaged using a Zeiss LSM 800 confocal microscope (Carl Zeiss AG, Oberkochen, Germany).

Sequence analysis. The overexpression of PLAGL2 was analyzed by the GEPIA database (14) and COSMIC database 
Table I. Sequences of the vectors.

\begin{tabular}{lc}
\hline Serial number & Sequence (5'-3') \\
\hline $\begin{array}{l}\text { PLAGL2-Homo } \\
\text {-506 (LV1) }\end{array}$ & CCACCAGTGTATGTACTGTGA \\
PLAGL2-Homo & CTGCAGACCTTTGAGAGTACC \\
-699 (LV2) & \\
PLAGL2-Homo & GGCGGTTCTATACTCGTAAGG \\
-808 (LV3) & \\
LV-NC & TTCTCCGAACGTGTCACGT \\
\hline
\end{tabular}

Table II. Primer sequences for RT-qPCR.

\begin{tabular}{ll}
\hline Gene detected & \multicolumn{1}{c}{ Sequence (5'-3') } \\
\hline GAPDH & F: GAAGGTGAAGGTCGGAGT \\
& R: CATGGGTGGAATCATATTGGAA \\
PLAGL2 & F: GAGTCAAGTGAAGTGCCAATGT \\
& R: TGAGGGCAGCTATATGGTCTC \\
FZD6 & F: TCTGCTGTCTTCTGGGTTGG \\
& R: CTGTAGCTCCTGTGCTGGTT \\
FZD7 & F: TTCTACCACAGACTTAGCCACAG \\
& R: CTCACTTCCAGGTCACTTCTCA \\
Wnt3 & F: TGACTTCGGCGTGTTAGTGT \\
Rnt6 & F: GTGCATGTGGTCCAGGATAG \\
& R: CGTCTCCCGAATGTCCTGTT \\
Wnt11 & F: GGAGTCGGCCTTCGTGTATG \\
& R: GCCCGTAGCTGAGGTTGTC \\
\end{tabular}

F, forward; R, reverse.

Table III. The thermocycling conditions used in qPCR.

\begin{tabular}{lcl}
\hline Temperature $\left({ }^{\circ} \mathrm{C}\right)$ & Time & \\
\hline 95 & $5 \mathrm{~min}$ & \\
95 & $30 \mathrm{sec}$ & T4 40 cycles \\
60 & $30 \mathrm{sec}$ & \\
72 & $30 \mathrm{sec}$ & \\
72 & $10 \mathrm{~min}$ & \\
4 & Hold & \\
\hline
\end{tabular}

(http:/cancer.sanger.ac.uk/cosmic/). The NCBI gene browser (https://www.ncbi.nlm.nih.gov/gene/) was used to find the human Wnt6 locus (Chr2: 218,858,382-218,875,674) and the Wnt6 promoter region (Chr2: 218,858,821-218,860,072). Candidate transcription factor binding sites were predicted by means of the JASPAR database (http://jaspar.genereg.net/).

ChIP. Chromatin immunoprecipitation (ChIP) was performed using an EZ-ChIP ${ }^{\text {тм }}$ ChIP kit (Merck Millipore, Darmstadt, Germany) following the manufacturer's protocol, including anti-RNA polymerase II (Merck Millipore; cat. no. 05-623B),
Table IV. Primer sequences for qPCR in ChIP assays.

\begin{tabular}{ll}
\hline Gene detected & \multicolumn{1}{c}{ Sequence (5'-3') } \\
\hline GAPDH & F: TACTAGCGGTTTTACGGGCG \\
& R: TCGAACAGGAGGAGCAGAGAGCGA \\
Wnt6-1 & F: TCTCTACTCTTCTTCCCAGCCCTT \\
& R: TCGGGCTGTGGGACCCGCCCGCTT \\
Wnt6-2 & F: CCAAGTCCGAGAGAGGCGAGGCGA \\
& R: GCGGGACTCTCGGGAGCGAGCCGT \\
Wnt6-3 & F: AGGAGACACAGGCGCTGGCTGCCC \\
& R: TCAGTGCGAGCGCGGCGAGCGCAA
\end{tabular}

F, forward; R, reverse.

anti-IgG(mouse) (MerckMillipore; cat.no.12-371B) andGAPDH primers (Merck Millipore; cat. no. 22-004). HCT116 cells $\left(2 \times 10^{7}\right)$ were crosslinked with $37 \%$ formaldehyde. The chromatin was cleaved into fragments between 200 and 600 bp by ultrasound. Anti-PLAGL2 was purchased from Abcam and qPCR was performed with the KOD SYBR ${ }^{\circledR}$ qPCR kit (Toyobo). Primer details are presented in Table IV. The levels of DNA were determined by the $2^{-\Delta \Delta \mathrm{Cq}}$ method.

Generation of luciferase reporter constructs. The promoter fragments of the WNT6 gene were generated by PCR using a forward primer with a $K p n \mathrm{I}(15)$ site inserted at the $5^{\prime}$ end and a reverse primer with a $B g l \mathrm{II}$ (15) site inserted at the $3^{\prime}$ end. PCR products were digested with $K p n \mathrm{I} / \mathrm{Bgl \textrm {II }}$ and cloned into a pGL3 firefly luciferase basic vector (Promega Corp., Madison, WI, USA) following the manufacturer's protocol.

Cell transfection and luciferase assays. HCT116 cells were transfected using Lipofectamine 2000 (Invitrogen; Thermo Fisher Scientific, Inc.) according to the manufacturer's instructions. Cells were then incubated at $37^{\circ} \mathrm{C}$ for $48 \mathrm{~h}$ before assaying for luciferase activity using the Dual-Luciferase Reporter assay system (Promega Corp.) according to the manufacturer's instructions. Firefly luciferase activity was normalized relative to Renilla luciferase activity for each transfection and calculated as the fold increase over pGL3 firefly luciferase basic vector (pGL3Basic). At least two independent transfections and two replicates per assay were performed for each individual construct.

Statistical analysis. The statistical analysis was performed by using SPSS 19.0 software (SPSS, Inc., Chicago, IL, USA). Data were imaged with GraphPad Prism 6 software (GraphPad Software, Inc., La Jolla, CA, USA) and expressed as the mean \pm SD. Differences between groups were compared with Student's t-test (when 2 groups) and one-way ANOVA (when $>2$ groups) was used, followed by Student-Newman-Keuls (SNK) method for comparing each two groups. $\mathrm{P}<0.05$ was considered to indicate a statistically significant difference.

\section{Results}

PLAGL2 is overexpressed in colorectal cancer. Using the Catalogue of Somatic Mutations in Cancer database (COSMIC; 

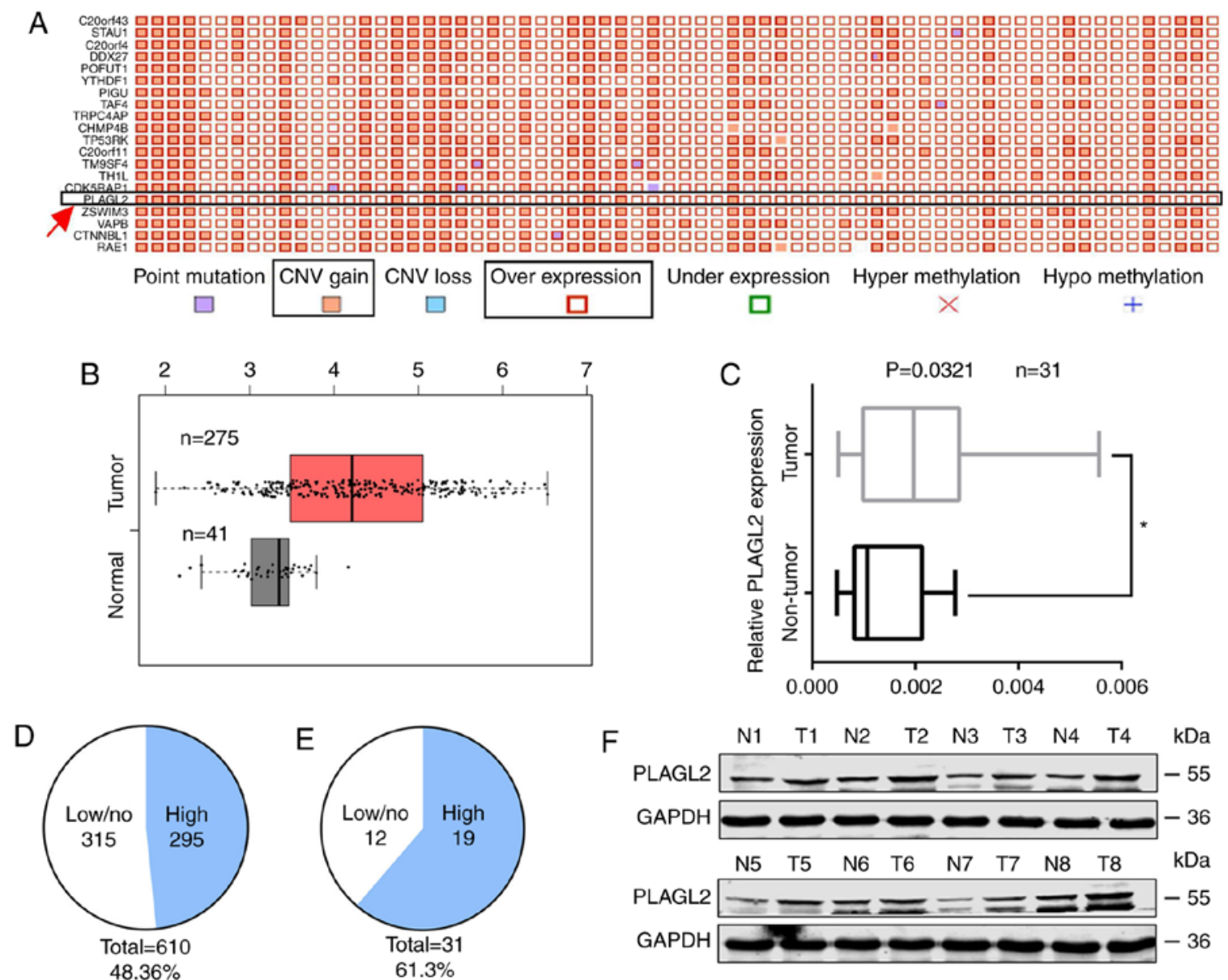

Figure 1. Expression of PLAGL2 in cancer tissues and pericarcinomatous tissues. (A) The top 20 genes that are overexpressed in CRC. This information was obtained from the COSMIC database. (B) The analysis of the mRNA of 275 tumor tissues and 41 normal tissues from the GEPIA database. (C) Expression in 31 pairs of cancer and pericarcinomatous tissues. (D and E) The percentages of the pairs with PLAGL2 overexpression. The information is from the COSMIC database and our research. (F) The western blot analysis of 8 pairs of cancer and pericarcinomatous tissues in which PLAGL2 was overexpressed in the tumor tissues. The data are expressed as the mean \pm SD for 3 experiments, each performed in duplicate, ${ }^{*} \mathrm{P}<0.05$.

http://cancer.sanger.ac.uk/cosmic/), overexpressed genes in colorectal cancer were screened and the top 20 were selected; PLAGL2 at position 16 was revealed (Fig. 1A). GEPIA analysis of the mRNA from 275 colon cancer specimens and 41 normal colonic tissues in TCGA revealed that the expression of PLAGL2 in cancer tissue was 1.235 -fold that of PLAGL2 in normal tissue (Fig. 1B). The mRNA of 31 colorectal cancer tissue samples and 31 adjacent normal tissue samples was examined by RT-qPCR. The expression of PLAGL2 in cancer tissue was 2.247-fold that of PLAGL2 in the normal tissues (Fig. 1C). In the COSMIC database, 295 gene fusion pairs exhibited PLAGL2 expression that was higher in cancer tissues than in normal tissues, accounting for $\sim 48.36 \%$ of the total number of tissues. In the 31 pairs of tissues used in this experiment, PLAGL2 was found in cancer tissues. Approximately 19 pairs had higher expression in cancer tissues than normal tissues, accounting for $\sim 61.3 \%$ of the total number of tissues (Fig. 1D and E). Eight of the 19 pairs of tissues in which PLAGL2 expression was higher in the cancer tissues than normal tissues were selected to detect the protein expression of PLAGL2 by western blot analysis. The expression of PLAGL2 in colorectal cancer tissue was significantly higher than that in the normal tissue adjacent to the tumor (Fig. 1F). These results indicated that PLAGL2 was overexpressed in colorectal cancer.
PLAGL2 influences the cell cycle and promotes the proliferation of colorectal cancer. Next, we sought to reveal the function of PLAGL2 in CRC. The CRC cell lines HCT116 and SW480 were selected and different vectors were applied to knock down PLAGL2. It was found that both in SW480 and HCT116 cells, the most efficient plasmid was PLAGL2-Homo-808 (LV3) (Fig. 2A and B). The PLAGL2-knockdown group (PL-LV3) was selected as the experimental group and the empty plasmid group (NC) was used as the control group for functional experiments. The results of the CCK- 8 assay revealed that in SW480 cells, the growth rate of the experimental group cells was significantly lower than that of the control group cells after $48 \mathrm{~h}(\mathrm{P}<0.05)$ and the difference among them was more pronounced with time $(\mathrm{P}<0.01)$. In HCT116 cells, from $72 \mathrm{~h}$ onwards, the growth rate of the experimental group of cells was significantly lower than that of the control group cells, with significant differences $(\mathrm{P}<0.05)$, and the differences among them were more obvious with time $(\mathrm{P}<0.01)$ (Fig. $2 \mathrm{C}$ and $\mathrm{D}$ ). Flow cytometry was used to detect the cell cycle. The results indicated that in the HCT116 and SW80 cells, the cells in the experimental group exhibited a prolonged G1 phase and the $\mathrm{S}$ phase was shortened (Fig. 2E and F) when compared with the control cells. Tumor formation experiments in nude mice indicated that the tumor volume in the untreated and the 

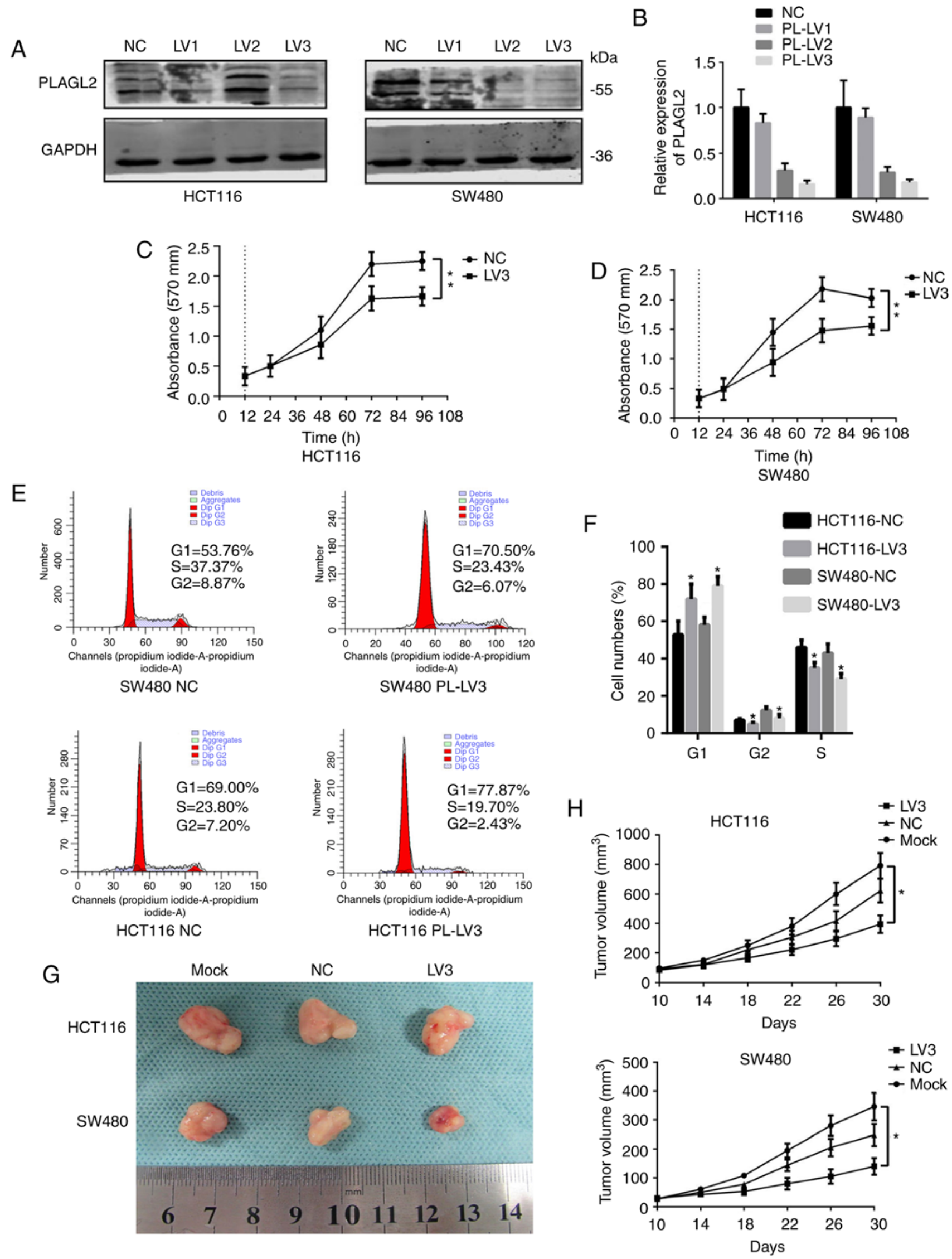

Figure 2. PLAGL2 influences the cell cycle and promotes the proliferation of colorectal cancer. (A and B) The verification of the efficiency of PLAGL2 knockdown with western blot analysis and RT-qPCR assays. (C and D) The CCK-8 assays for HCT116 and SW480 colorectal cancer cells. LV3 indicates that PLAGL2 was knocked down, and NC indicates the control group. (E and F) The cell cycle was analyzed with flow cytometry. LV3 indicates PLAGL2 was knocked down, and NC indicates the control group. (G) Tumor formation experiments in BALB/C nude mice. Mock indicates the original cancer cells, LV3 indicates PLAGL2 was knocked down, and NC indicates the control group. (H) The growth curve of the tumor in tumor formation experiments. The data are expressed as the mean $\pm \mathrm{SD}$ for 3 experiments, each performed in duplicate, ${ }^{*} \mathrm{P}<0.05$. 
A

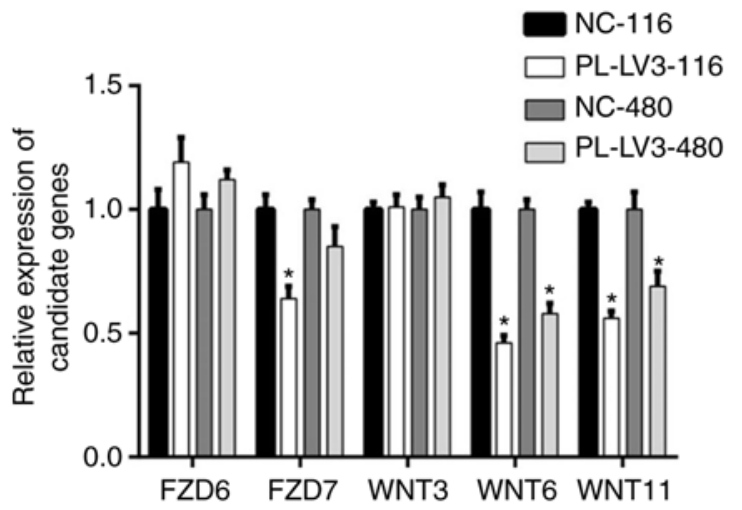

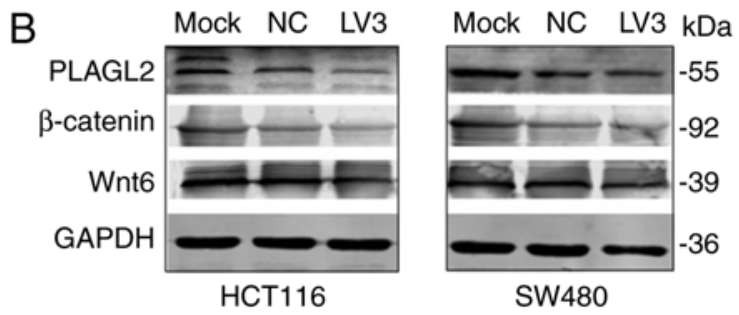

C

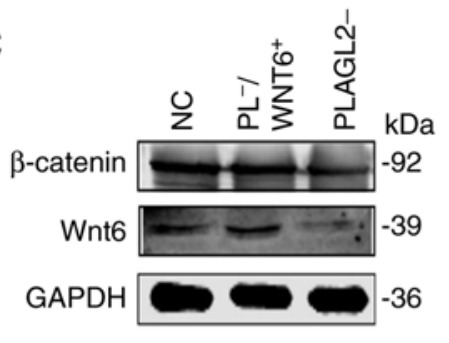

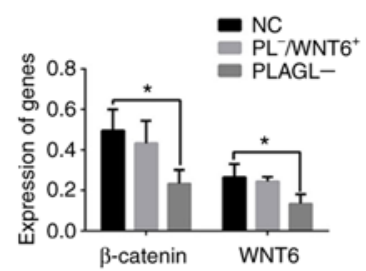
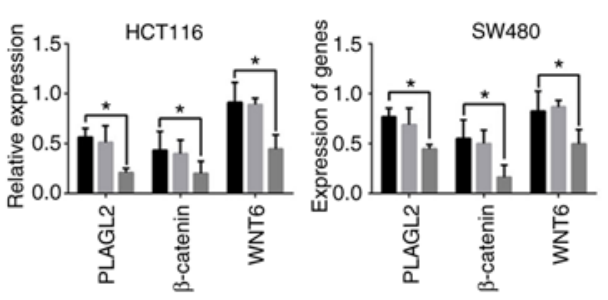

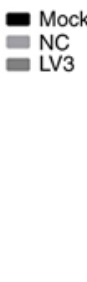

D

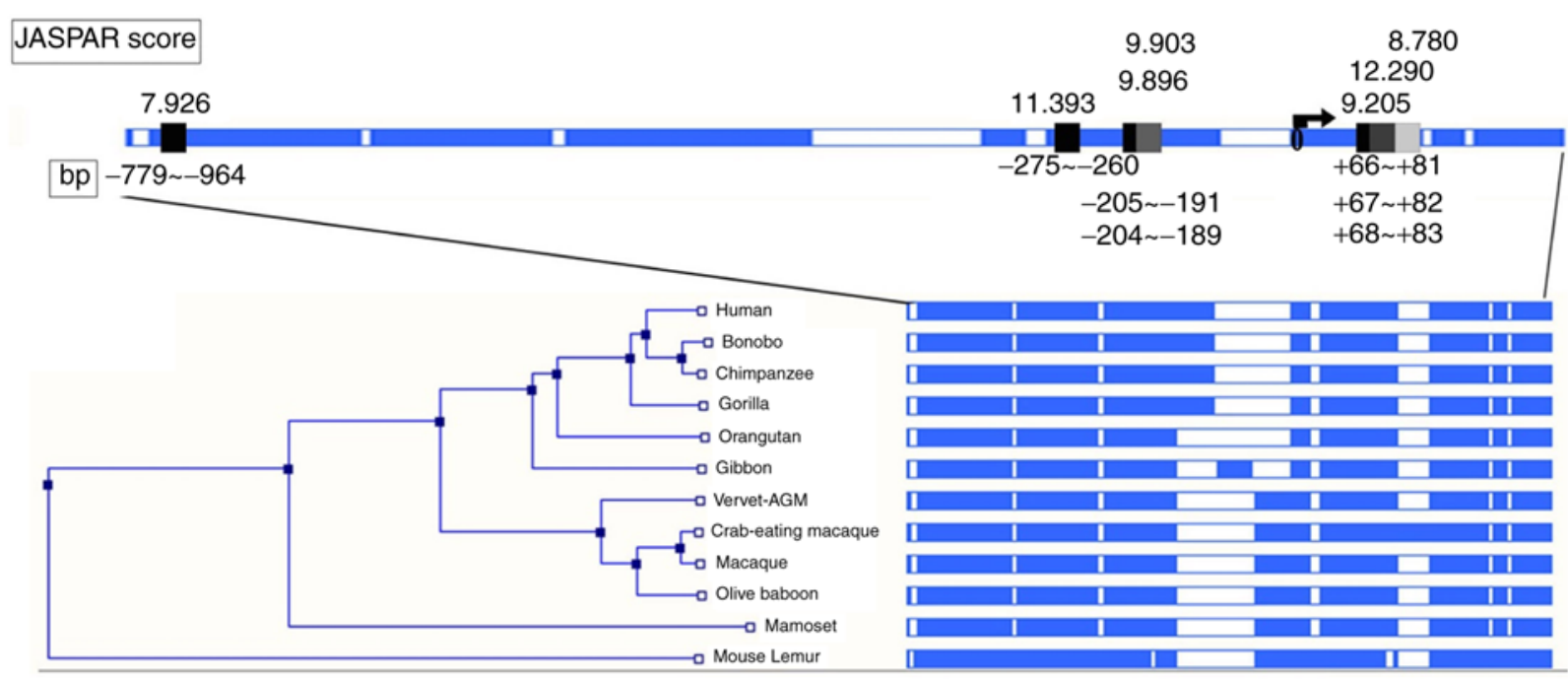

>hg38_knownGene_uc002vjc.2 range=chr2:218858821-218860037 5'pad=03'pad=0 strand=+repeatMasking=none

Figure 3. Screening of signaling pathway factors and prediction about the promoter region. (A) The factors in the Wnt pathway were screened and the one that was related to PLAG2 was choosen using RT-qPCR assays. (B) With western blot assays, the expression levels of PLAGL2, Wnt6 and $\beta$-catenin were revealed to have a positive correlation. Mock indicates the original cancer cells, LV3 indicates PLAGL2 was knocked down, and NC indicates the control group. (C) With western blot assays, the expression levels of Wnt6 and $\beta$-catenin were revealed to have a positive correlation. NC indicates the control group, PLAGL2 indicates that PLAGL2 was knocked down, and PL/WNT6 ${ }^{+}$indicates PLAGL2 was knocked down and WNT6 was overexpressed. (D) Prediction about the promoter region that can bind with PLAGL2, which was predicted by the JASPAR database. The data are expressed as the mean \pm SD for 3 experiments, each performed in duplicate, $\mathrm{P}<0.05$.

control groups was greater than that in the experimental group (Fig. 2G), and the growth curve indicated that the growth rate of the control group was greater than that of the experimental group (Fig. 2H). These results indicated that PLAGL2 affected the development of colorectal cancer in vitro and in vivo.

PLAGL2 promotes the Wnt/ $\beta$-catenin pathway. PLAGL2 plays as an important role in other tumors, where it can always activate the $\mathrm{Wnt} / \beta$-catenin pathway, and the $\mathrm{Wnt} / \beta$-catenin pathway is one of most active pathways in colorectal cancer. Several key factors that are active in the Wnt/ $\beta$-catenin pathway were selected and primers were designed. The mRNA of SW480 and HCT116 cells was extracted and the expression was detected with RT-qPCR. It was found that the expression of Wnt6 and Wnt11 was significantly decreased after PLAGL2 knockdown (Fig. 3A). While Wnt11 mainly regulates the $\mathrm{Wnt} / \mathrm{Ca}^{2+}$ pathway, Wnt6 regulates the Wnt/ $\beta$-catenin pathway. A western blot assay was used to detect changes in the expression of Wnt6 and $\beta$-catenin protein before and after PLAGL2 knockdown. The results revealed that the expression of Wnt6 and $\beta$-catenin 
A >hg38_knownGene_uc002vjc. 2 range=chr 2:218858821-218874233 5'pad=03'pad=0 strand=+repeatMasking=none

cccgcccaaactcctcattcctgggaagttttctctcttacagtcaacaaacctgtcaaacgtct ccettccagccegtccccattcctcagctcctctttctccccctcaccctctctactcttcttcc cagccettccttgccccyactccaggcggccgcgagcggeggggggctccaagtccgagagaggcga ggcgagggggcgaagcgggcgggtcccacagcccgaagcgcgctggggcccegccceggcacccegct cccgccetccgctgcgetccgcgccagc cgccceggggcgcacggctcgetccegagagtcccgctgc

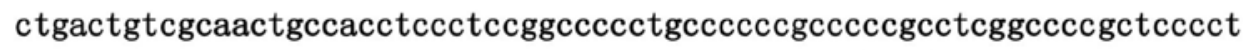
cccacctcegecceggetctgatttcttct ccegagegagc TCCGCAGGAGACACAGGCGCTGGCTG CCCCGTCCGCTCTCCGCCTCCGCCGCGCCCTCCTCGCCCGGGATGGGCCCCCCCGCCGCCGCCGGATC CCTCGCCTCCCGGCCGCCGCCGTTGCGCTCGCCGCGCTCGCACTGAAGCCCGGGCC

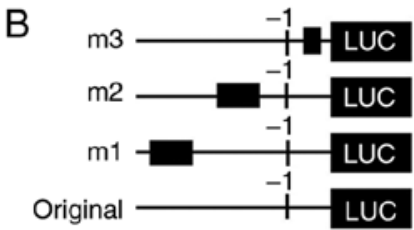

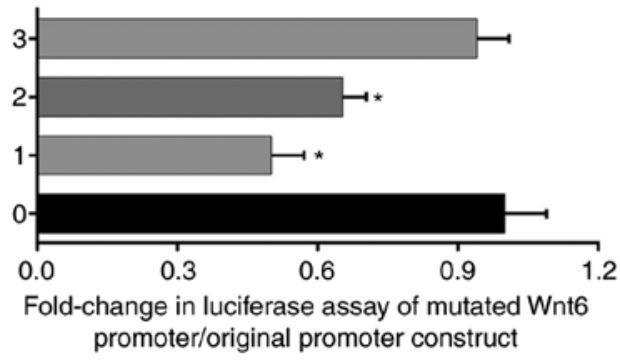

Mutation 1

Mutation 2

Mutation 3

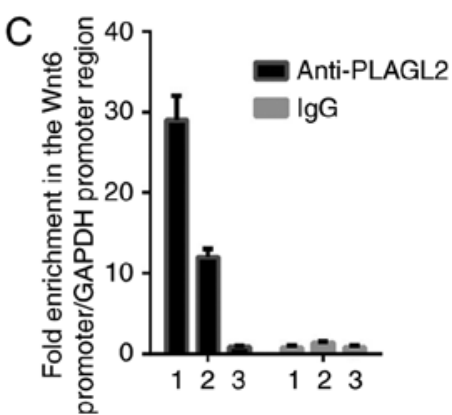

Figure 4. Verification that PLAGL2 activates Wnt6 as a transcription factor using luciferase reporter and ChIP assays. (A) Three ideal binding regions that were predicted by the JASPAR database. (B) In HCT116 cells, the changes in the activity of the promoter when three mutations were made in different promoter regions were revealed. The promoter activity was assessed using the luciferase reporter assay. (C) PLAGL2 was enriched in the Wnt6 promoter in Wnt6-expressing HCT116 cells (ChIP analysis. The data are expressed as the mean \pm SD for 3 experiments, each performed in duplicate, ${ }^{*}<0.05$.

proteins decreased with the knockdown of PLAGL2 (Fig. 3B). Wnt6 was overexpressed in HCT116 cells when PLAGL2 was knocked down and the two groups were compared. The WB assays revealed that $\beta$-catenin was increased when WNT6 was overexpressed but PLAGL2 was knock down. It revealed that PLAGL2 activated the Wnt/ $\beta$-catenin pathway by promoting the expression of WNT6 (Fig. 3B). The sequence 1,000 bp upstream and $216 \mathrm{bp}$ upstream of the WNT6 gene was used to make predictions using the JASPER database, indicating that the WNT6 upstream sequence was highly conserved among different species and that the conserved region had 7 possible binding domains for the PLAGL2 gene (Fig. 3C).

PLAGL2 binds to the promoter region of Wnt6 and actives it. The three-ideal binding region mutation analyses predicted by the JASPAR database were selected; the horizontal lines represent possible binding sites and mutation regions of PLAGL2 and Wnt6 (Fig. 4A). The luciferase assay results revealed that after mutation of the predicted binding regions, the promoter activity was decreased. Compared to the activity of the original promoter region, mutation 1 resulted in a $\sim 50 \%$ reduction in promoter activity, mutation 2 resulted in a $\sim 35 \%$ reduction, and mutation 3 resulted in a $\sim 10 \%$ reduction (Fig. 4B). In HCT116 cells, we applied ChIP assays to detect the binding of PLAGL2 to the Wnt6 promoter region. It was revealed that PALGL2 strongly bound to the Wnt6 promoter region in HCT116 cells, with a $\sim 28$ and $\sim 12$-fold enrichment compared to the GAPDH control (Fig. 4C). The results of immunofluorescence also revealed that the PLAGL2 proteins were located in the cell nucleus (Fig. 5A). These results indicated that PLAGL2 could activate Wnt6 expression in colorectal cancer cells, activating the $\mathrm{Wnt} / \beta$-catenin pathway.

\section{Discussion}

The polymorphic adenoma-like protein 2 (PLAGL2), located on chromosome 20q21.11, is a zinc finger protein derived from the PLAG gene family. The protein can function as a transcription factor to activate the expression of some oncogenes and cancer-promoting signaling pathways by activating promoters, thereby inhibiting cell differentiation and increasing the speed of cell self-replication. The carcinogenic effects of PLAGL2 have been found in many malignancies, including acute myeloid leukemia, neurogenic stromal tumor, lung and breast cancer (7-9,16-18). For the relationship between PLAGL2 and colorectal cancer, more studies are required. In the present study, the information we collected by screening the COSMIC database (19-21) and GEPIA database and by RT-qPCR and WB demonstrated that PLAGL2 was overexpressed in colorectal cancer tissues.

As a proto-oncogene, PLAGL2 is overexpressed in colorectal cancer, and it can be reasonably speculated that it plays a role in the development of colorectal cancer. However, PLAGL2 can act as a transcription factor in many tumors and activate some cancer-promoting pathways relating to cancer, such as the Wnt/ $\beta$-catenin pathway.

The $W n t / \beta$-catenin pathway is a very active signaling pathway in colorectal cancer, and it can promote the proliferation, cell cycle, apoptosis, invasion and migration of colorectal cancer after activation (22). $\beta$-catenin can be phosphorylated by GSK3- $\beta$ and ultimately be hydrolyzed by the ubiquitin-proteasome pathway. The binding of the Wnt signaling pathway ligand to the paired frizzled-like receptors inhibits hydrolysis of the $\beta$-catenin complex, including APC, AXIN and GSK3- $\beta$, and a series of reactions leads to the stabilization of $\beta$-catenin 
A $\mathrm{HCT} 116$
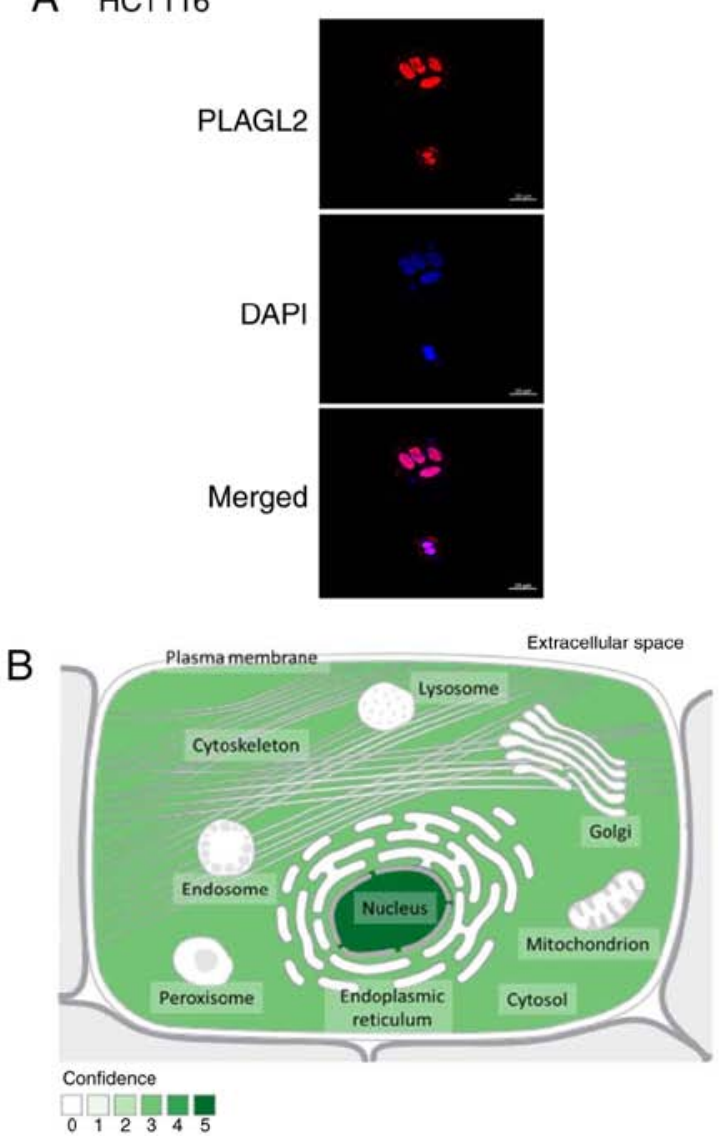

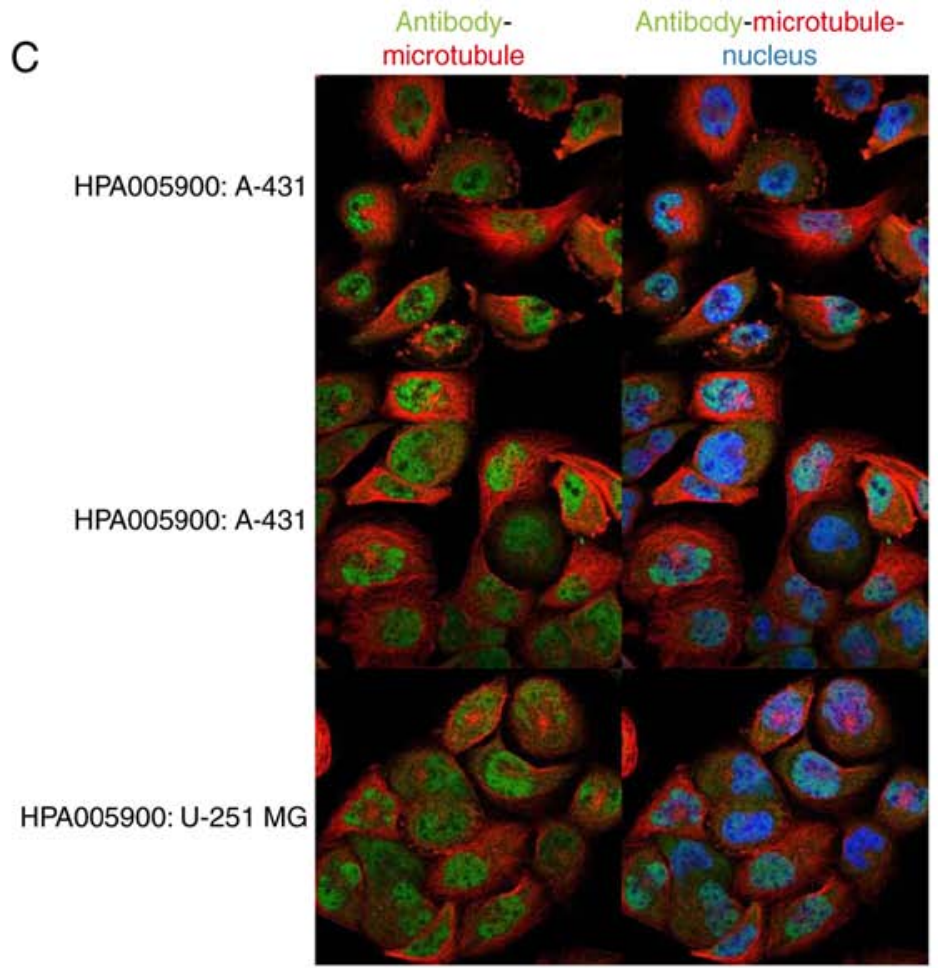

C

Figure 5. PLAGL2 proteins are located in cell nucleus. (A) The immunofluorescence assay revealed that the proteins PLAGL2 in the HCT116 cells were located in the cell nucleus. (B) The GeneCards database revealed the subcellular locations for the PLAGL2 gene, the confidence was 5 in the compartment nucleus and the confidence was 3 in the compartment cytosol. (C) The immunofluorescence assay results of the Human Protein Atlas database revealed that the PLAGL2 proteins were located in the nucleoplasm.

in the nucleus and eventual activation of the downstream target gene. When the $\mathrm{Wnt} / \beta$-catenin pathway is activated, $\beta$-catenin is translocated into the nucleus and binds to the transcription factor TCF/LEF in the nucleus, which leads to the activation of expression of the downstream target genes, such as a MMP-7, CCND1, c-Myc and survivin. The activation of these downstream genes can promote the development of colorectal cancer (23-26). For example, the proto-oncogene c-Myc can be activated by $\beta$-catenin and inhibited by wild-type APC. The dependence of $\beta$-catenin-mediated c-Myc proto-oncogene expression will maintain the initial phenotype of colorectal cancer cells by inhibiting p21 expression and disrupting cell differentiation (27). $\beta$-catenin can also regulate the expression of CCND1. CCND1 is an important G1 phase cyclin, and $\beta$-catenin can increase the expression of CCND1 after it enters the nucleus. CCND1 accumulates in the nucleus and promotes cells to enter the $S$ phase from the $\mathrm{G} 1$ phase. The cells enter the $\mathrm{S}$ phase and hydrolyze, which accelerates the cell cycle $(28,29)$. MMP-7 which functions as a downstream target gene for the Wnt pathway is also activated when the Wnt pathway is activated. MMP-7 is a member of the MMP family, and MMPs are $\mathrm{Zn}^{2+}$-dependent proteolytic enzymes that can degrade a variety of basement membrane and extracellular matrix components. It plays an important role in tumor invasion and metastasis. Survivin, a member of the apoptotic inhibitor protein family, inhibits apoptosis and expression in tumors and enhances tumor cell viability (30). High expression of survivin was also revealed when the Wnt pathway was activated.

It was revealed that the $\mathrm{WNT} / \beta$-catenin pathway plays an important role in colorectal cancer. This study demonstrated that PLAGL2 was related to the activation of the WNT/ $\beta$-catenin pathway in colorectal cancer. Now, the question that remains is how PLAGL2 regulates the expression of the $\mathrm{WNT} / \beta$-catenin pathway. PLAGL2 is located on chromosome 20q11.21 and contains the initiation codon ATG and the stop codon TAG, without the presence of the AATAAA polyadenylation signal. Its open reading frame encodes 496 amino acid residues. The protein consists of seven zinc finger structure consensus sequences at the amino acid terminus and a carboxylic end rich in proline and serine (4). The zinc finger structure is often found in DNA-binding proteins. It consists of a ring containing approximately 30 amino acids and a $\mathrm{Zn}^{2+}$ coordinated to 4 Cys or 2 Cys and 2 His on the ring, forming a structure like a finger (31). The zinc finger has a pair of cysteine residues at the $\mathrm{N}$-terminus and a pair of histidine residues at the $\mathrm{C}$-terminus. The zinc finger structure can specifically recognize the DNA sequence through the conserved sequence at the $\mathrm{N}$-terminus, and the $\mathrm{C}$-terminus has a transactivation function. The transcriptional activity of PLALG2 is 
activated by binding to the bidirectional consensus sequence GRGGC(N)(6-8)GGG (32), and its protein contains seven zinc finger structures, of which zinc finger structure 3 is mainly responsible for recognizing the aforementioned. In the sequence, zinc finger structures 6 and 7 are the cores that bind to proteins (33).

It is known from the structural features of PLAGL2 that it recognizes the promoter region of genes and promotes gene transcription using the C-terminal activation functions. Some researchers have claimed that PLAGL2 can be secreted to the medium in vitro, but as a transcription factor, all the aforementioned processes occur in the nucleus (9,34-36). The introduction of PLAGL2 in PubMed revealed that most PLAGL2 proteins are located in the cell nucleus. The data from the GeneCards database (https://www.genecards.org/) revealed the same results (Fig. 5B). The immunofluorescence results from The Human Protein Atlas (https://www. proteinatlas.org/) revealed that the proteins of PLAGL2 are surrounded by karyotheca (Fig. 5C).

In the present study, it was demonstrated through a ChIP assay, that PLAGL2 could be combined with the promoter region of WNT6 in the nucleus. The luciferase assay revealed that PLAGL2 could activate the transcription of WNT6 by binding to the WNT6 promoter region.

Wnt6 protein expression activates the Wnt $/ \beta$-catenin pathway. The activation of the $\mathrm{Wnt} / \beta$-catenin pathway leads to the overexpression of a series of target proteins, which may play important roles in the development of colorectal cancer.

In summary, PLAGL2 is an oncogene that is active in a variety of malignancies. It is rarely expressed in normal adult tissues and is active in embryos, stem cells and tumors (5). Further research on PLAGL2 may provide a new target for the targeted therapy of colorectal cancer.

\section{Acknowledgements}

Not applicable.

\section{Funding}

The present study was supported by the National Nature Science Foundation of China (no. 81773130), The New Xiangya Talent Projects of the Third Xiangya Hospital of Central South University (no. JY201508) and The Key Projects of Postgraduate Independent Exploration and Innovation of Central South University (2018zzts050).

\section{Availability of data and materials}

The bioinformatics data analysis and figures used in our study can be obtained from the following websites: GEPIA database (http://gepia.cancer-pku.cn/); COSMIC database (http:// cancer.sanger.ac.uk/cosmic/); The NCBI gene browser (https:// www.ncbi.nlm.nih.gov/gene/); JASPAR database (http://jaspar. genereg.net/). Genecards database (https://www.genecards. org/); The Human Protein Atlas (https://www.proteinatlas. org/). All the data and figures from these websites above are open and there are no copyright disputes. The datasets used during the present study are available from the corresponding author upon reasonable request.

\section{Authors' contributions}

Article checking and project design were carried out by $\mathrm{GH}$ and XL; the experiment design, the writing and the cell experiments were performed by NL and DL; the tissue experiments and the animal experiments were performed by YD and CS; the figure editing, the statistical analysis and the specimen collection was carried out by CY and CL. All authors read and approved the manuscript and agree to be accountable for all aspects of the research in ensuring that the accuracy or integrity of any part of the work are appropriately investigated and resolved.

\section{Ethics approval and patient consent for participation}

Signed consent forms were provided by each patient, and the study was approved by The Institute Research Medical Ethics Committee of Central South University (Changsha, Hunan). All animal protocols in this study were approved by the Animal Ethics Committee of Central South University (Changsha, China).

\section{Patient consent for publication}

Not applicable.

\section{Competing interests}

The authors declare that they have no competing interests.

\section{References}

1. Siegel R, Desantis C and Jemal A: Colorectal cancer statistics, 2014. CA Cancer J Clin 64: 104-117, 2014.

2. Torre LA, Bray F, Siegel RL, Ferlay J, Lortet-Tieulent J and Jemal A: Global cancer statistics, 2012. CA Cancer J Clin 65: 87-108, 2015.

3. Wezensky SJ, Hanks TS, Wilkison MJ, Ammons MC, Siemsen DW and Gauss KA: Modulation of PLAGL2 transactivation by positive cofactor 2 (PC2), a component of the ARC/mediator complex. Gene 452: 22-34, 2010.

4. Kas K, Voz ML, Hensen K, Meyen E and Van de Ven WJ: Transcriptional activation capacity of the novel PLAG family of zinc finger proteins. J Biol Chem 273: 23026-23032, 1998.

5. Furukawa T, Adachi Y, Fujisawa J, Kambe T, Yamaguchi-Iwai Y, Sasaki R, Kuwahara J, Ikehara S, Tokunaga R and Taketani S: Involvement of PLAGL2 in activation of iron deficientand hypoxia-induced gene expression in mouse cell lines. Oncogene 20: 4718-4727, 2001.

6. Soto A, Arce A, M KK and Vera JH: Effect of the cation and the anion of an electrolyte on the solubility of DL-aminobutyric acid in aqueous solutions: Measurement and modelling. Biophys Chem 73: 77-83, 1998.

7. Landrette SF, Kuo YH, Hensen K, Barjesteh van Waalwijk van Doorn-Khosrovani S, Perrat PN, Van de Ven WJ, Delwel R and Castilla LH: Plag1 and Plag12 are oncogenes that induce acute myeloid leukemia in cooperation with Cbfb-MYH11. Blood 105: 2900-2907, 2005.

8. Yang YS, Yang MC and Weissler JC: Pleiomorphic adenoma gene-like 2 expression is associated with the development of lung adenocarcinoma and emphysema. Lung Cancer 74: 12-24, 2011.

9. Zheng H, Ying H, Wiedemeyer R, Yan H, Quayle SN, Ivanova EV, Paik JH, Zhang H, Xiao Y, Perry SR, et al: PLAGL2 regulates Wnt signaling to impede differentiation in neural stem cells and gliomas. Cancer Cell 17: 497-509, 2010.

10. Guo J, Wang M, Wang Z and Liu X: Overexpression of pleomorphic adenoma gene-like 2 is a novel poor prognostic marker of prostate cancer. PLoS One 11: e0158667, 2016. 
11. Liu B, Lu C, Song YX, Gao P, Sun JX, Chen XW, Wang MX, Dong YL, Xu HM and Wang ZN: The role of pleomorphic adenoma gene-like 2 in gastrointestinal cancer development, progression, and prognosis. Int J Clin Exp Pathol 7: 3089-3100, 2014.

12. Su C, Li D, Li N, Du Y, Yang C, Bai Y, Lin C, Li X and Zhang Y: Studying the mechanism of PLAGL2 overexpression and its carcinogenic characteristics based on 3'-untranslated region in colorectal cancer. Int J Oncol, 2018.

13. Livak KJ and Schmittgen TD: Analysis of relative gene expression data using real-time quantitative PCR and the 2(-Delta Delta C(T)) method. Methods 25: 402-408, 2001.

14. Tang Z, Li C, Kang B, Gao G, Li C and Zhang Z: GEPIA: A web server for cancer and normal gene expression profiling and interactive analyses. Nucleic Acids Res 45: W98-W102, 2017

15. Schwitalla S, Fingerle AA, Cammareri P,Nebelsiek T, Göktuna SI Ziegler PK, Canli O, Heijmans J, Huels DJ, Moreaux G, et al: Intestinal tumorigenesis initiated by dedifferentiation and acquisition of stem-cell-like properties. Cell 152: 25-38, 2013.

16. Daughaday WH: The possible autocrine/paracrine and endocrine roles of insulin-like growth factors of human tumors. Endocrinology 127: 1-4, 1990.

17. Hensen K, Van Valckenborgh IC, Kas K, Van de Ven WJ and Voz ML: The tumorigenic diversity of the three PLAG family members is associated with different DNA binding capacities. Cancer Res 62: 1510-1517, 2002.

18. Kas K, Voz ML, Roijer E, Aström AK, Meyen E, Stenman G and Van de Ven WJ: Promoter swapping between the genes for a novel zinc finger protein and beta-catenin in pleiomorphic adenomas with $\mathrm{t}(3 ; 8)(\mathrm{p} 21 ; \mathrm{q} 12)$ translocations. Nat Genet 15: 170-174, 1997.

19. Forbes SA, Beare D, Gunasekaran P, Leung K, Bindal N, Boutselakis H, Ding M, Bamford S, Cole C, Ward S, et al: COSMIC: Exploring the world's knowledge of somatic mutations in human cancer. Nucleic Acids Res 43: D805-D811, 2015.

20. Forbes SA, Beare D, Bindal N, Bamford S, Ward S, Cole CG Jia M, Kok C, Boutselakis H, De T, et al: COSMIC: High-resolution cancer genetics using the catalogue of somatic mutations in cancer. Curr Protoc Hum Genet 91: 1-10, 2016.

21. Forbes SA, Beare D, Boutselakis H, Bamford S, Bindal N, Tate J, Cole CG, Ward S, Dawson E, Ponting L, et al: COSMIC: Somatic cancer genetics at high-resolution. Nucleic Acids Res 45: D777-D783, 2017.

22. Batlle E, Henderson JT, Beghtel H, van den Born MM, Sancho E, Huls G, Meeldijk J, Robertson J, van de Wetering M, Pawson T and Clevers H: Beta-catenin and TCF mediate cell positioning in the intestinal epithelium by controlling the expression of EphB/ephrinB. Cell 111: 251-263, 2002.

23. Anderson CB, Neufeld KL and White RL: Subcellular distribution of Wnt pathway proteins in normal and neoplastic colon. Proc Nati Acad Sci USA 99: 8683-8688, 2002.

24. Munemitsu S, Albert I, Souza B, Rubinfeld B and Polakis P: Regulation of intracellular beta-catenin levels by the adenomatous polyposis coli (APC) tumor-suppressor protein. Proc Nat Acad Sci USA 92: 3046-3050, 1995.
25. Rosin-Arbesfeld R, Townsley F and Bienz M: The APC tumour suppressor has a nuclear export function. Nature 406: 1009-1012, 2000.

26. Kolligs FT, Bommer G and Goke B: Wnt/beta-catenin/tcf signaling: A critical pathway in gastrointestinal tumorigenesis. Digestion 66: 131-144, 2002.

27. van de Wetering M, Sancho E, Verweij C, de Lau W, Oving I, Hurlstone A, van der Horn K, Batlle E, Coudreuse D, Haramis AP, et al: The beta-catenin/TCF-4 complex imposes a crypt progenitor phenotype on colorectal cancer cells. Cell 111: 241-250, 2002.

28. Sansom OJ, Meniel VS, Muncan V, Phesse TJ, Wilkins JA, Reed KR, Vass JK, Athineos D, Clevers H and Clarke AR: Myc deletion rescues Apc deficiency in the small intestine. Nature 446: 676-679, 2007.

29. Shtutman M, Zhurinsky J, Simcha I, Albanese C, D'Amico M, Pestell R and Ben-Ze'ev A: The cyclin D1 gene is a target of the beta-catenin/LEF-1 pathway. Proc Nati Acad S USA 96: 5522-5527, 1999

30. Kawasaki H, Toyoda M, Shinohara H, Okuda J, Watanabe I, Yamamoto T, Tanaka K, Tenjo T and Tanigawa N: Expression of survivin correlates with apoptosis, proliferation, and angiogenesis during human colorectal tumorigenesis. Cancer 91: 2026-2032, 2001

31. Wolfe SA, Nekludova L and Pabo CO: DNA recognition by Cys2His2 zinc finger proteins. Annu Rev Biophys Biomol Struct 29: 183-212, 2000.

32. Van Dyck F, Delvaux EL, Van de Ven WJ and Chavez MV: Repression of the transactivating capacity of the oncoprotein PLAG1 by SUMOylation. J Biol Chem 279: 36121-36131, 2004.

33. Voz ML, Agten NS, Van de Ven WJ and Kas K: PLAG1, the main translocation target in pleomorphic adenoma of the salivary glands, is a positive regulator of IGF-II. Cancer Res 60: 106-113, 2000.

34. Strubberg AM, Veronese Paniagua DA, Zhao T, Dublin L, Pritchard T, Bayguinov PO, Fitzpatrick JAJ and Madison BB: The zinc finger transcription factor PLAGL2 enhances stem cell fate and activates expression of ASCL2 in intestinal epithelial cells. Stem Cell Reports 11: 410-424, 2018.

35. Van Dyck F, Declercq J, Braem CV and Van de Ven WJ: PLAG1, the prototype of the PLAG gene family: Versatility in tumour development (review). Int J Oncol 30: 765-774, 2007.

36. Guo Y, Yang MC, Weissler JC and Yang YS: Modulation of PLAGL2 transactivation activity by Ubc9 co-activation not SUMOylation. Biochem Biophys Res Commun 374: 570-575, 2008.

This work is licensed under a Creative Commons Attribution-NonCommercial 4.0 International (CC BY-NC 4.0) License. 